\title{
A TOMADA DE DECISÃO COM O IOWA GAMBLING TASK
}

\author{
DECISION MAKING WITH THE IOWA GAMBLING TASK
}

Rui Alexandre Paquete Paixão

Doutor em Psicologia. Professor na Universidade de Coimbra. Coimbra, Portugal.

ruipaixao@netcabo.pt

RESUMO I Este artigo analisa os padrões de tomada de decisão com lowa Gambling Task (IGT) e a hipótese do marcador somático. A tarefa experimental com o IGT é apresentada e analisados os resultados obtidos com a população de controlo nos estudos clínicos com esta tarefa onde se evidenciam tomadas de decisão desvantajosas semelhantes às encontradas nas populações clínicas. Estas populações de controlo apresentam características sociodemográficas específicas e relativamente comuns, nomeadamente um baixo nível económico. Considerando estes dados, a hipótese discutida neste trabalho é a de que a experiência de vida estabelecida pela baixa renda pode constituir uma variável fundamental no processo de tomada de decisão. A análise desta variável é feita tomando por referência os resultados obtidos num outro estudo onde estes padrões de decisão aparecem relacionados com essa variável (Paixão, 2016). Nesse estudo, os indivíduos nestas condições evidenciam um padrão de decisão marcado pela escolha sistemática da recompensa imediata, independentemente dos custos futuros dessa decisão. Finalmente, estes padrões são discutidos considerando a sua relação com as experiências de vida marcadas por múltiplas privações.

Palavras-chave: marcador somático; IGT; decisão; Risco e incerteza

\begin{abstract}
This paper analyses the decision making patterns with the lowa Gambling Task (IGT) and the somatic marker hypothesis. The experimental task with IGT is presented, as well the fact that some subjects related to control groups in clinical studies with the task show disadvantageous decision similar to those found in clinical populations. However, these populations present a specific socio demographic feature, namely a very low income level. Considering this data, our hypothesis is that life experience set by low income is an important variable in the decision making process. The analysis of this variable is preformed considering the results obtained in a study where these patterns decisions where related with low income (Paixão, 2016). In this study subjects show a decision pattern marked by immediate reward, regardless the future costs of such decision. Finally, these patterns are discussed considering their relationship with life experiences of multiple privations.
\end{abstract}

Keywords: somatic marker; IGT; decision; risk and uncertainty 
Todos os dias somos confrontados com problemas e situações que exigem uma decisão mais ou menos fundamental para $\circ$ nosso futuro. Sabemos, por vezes, ou pelo menos conseguimos calcular, que essas decisões implicam ganhos e custos prováveis mas, muitas vezes, a situação é de tal ordem que - quadro das consequências da decisão é nos completamente desconhecido, embora mesmo nestas situações a tendência seja a de procurarmos cenários possíveis, onde as diferentes escolhas são avaliadas e os diferentes resultados pensados. Pelo menos é assim que temos tendência a pensar o nosso comportamento.

Os processos decisionais são, de qualquer modo, uma problemática fundamental da vida Humana e por essa razão têm sido o foco de múltiplos estudos em diversas áreas científicas, com particular destaque para a economia e psicologia, estando inclusivamente na origem do primeiro prémio Nobel atribuído a um psicólogo: Daniel Kahneman, em 2002, pelo seu trabalho sobre decisões envolvendo riscos, particularmente sobre o modo como as pessoas avaliam perdas e ganhos prováveis. $O$ trabalho de Kahneman foi desenvolvido em conjunto com Amos Tversky, que morreu antes do reconhecimento pela Academia Sueca (em 1996). A obra notável destes investigadores encontra-se divulgada em português, na obra "Pensar, depressa e Devagar", editada em 2012 pelo Círculo dos Leitores, e constitui um modelo que questiona diretamente, na área da economia, a racionalidade atribuída classicamente aos processos de decisão, nomeadamente a alguns dos pressupostos da teoria da utilidade esperada.

Na área da psicologia clínica, têm sido estudados outros modelos decisionais que tentam analisar 0 papel das emoções nestes processos. A Hipótese do Marcador Somático, tal como formalizada por Bechara, Damasio e Damasio (2000), debruça-se exatamente sobre isso, isto é, sobre a possibilidade de existirem mecanismos emocionais (conscientes ou inconscientes) que medeiam o processo decisional.

Segundo esta hipótese, as decisões são assumidas em função das "avaliações emocionais" que fazemos dos ganhos (recompensas) e dos custos (punições), associados a cada uma das possibilidades de resposta, constituindo isso as diretrizes principais que guiam o nosso comportamento nas aprendizagens da vida real. Neste processo, as emoções funcionam como sinalizadores automáticos que, quando ativados, marcam com um determinado valor as diferentes alternativas, facilitando 0 processo de decisão e resolvendo os custos de um processo estritamente racional. $O$ processo decisional seria, assim, dominado pelas mudanças fisiológicas que acontecem em resposta a determinados estímulos emocionais, despertados por memórias ou por acontecimentos, $\bigcirc$ que constituiria $\circ$ acontecimento somático (Bechara, 2003).

A hipótese assenta em três eixos: (1) O sistema decisional é uma operação neuronal, dependente de avaliações sensoriais conscientes ou inconscientes; (2) As operações cognitivas envolvem a atenção, a memória de trabalho e a emoção; (3) Os aspetos mais racionais na tomada de decisão são uma função do conhecimento disponível sobre a situação, armazenado em córtices de elevada-ordem e em alguns núcleos subcorticais (Bechara, Damasio, \& Damasio, 2000).

carácter neuropsicológico do modelo prende-se com a sua origem, já que serviu inicialmente para descrever o comportamento de pacientes com lesões ventromediais pré-frontais. Estes pacientes, com lesões que parecem afetar essencialmente os processos emotivos e sensoriais, são normais em termos de aprendizagem, memória, linguagem e atenção, mas evidenciam uma grande incapacidade para aprender com a repetição dos erros, desenvolvendo padrões de tomada de decisão inadequados (ou desvantajosos) com implicações graves para a sua vida financeira e social (família e amigos) (Bechara, 2003).

Segundo o modelo, a falha do marcador somático está na origem destes padrões, orientando o sujeito para decisões dominadas pelo ganho imediato, sem grande consideração pelas consequências futuras, como se adquirissem uma "miopia para o futuro" (Damasio, 1994).

É neste contexto que Bechara, Damasio, Damasio e Anderson (1994) desenvolvem uma tarefa experimental que ganhará, já no século $X X I$, grande importância no meio científico da psicopatologia e da neuropsicologia (Paixão \& Areias, no prelo). A tarefa, conhecida pela sigla IGT (lowa Gambling 
Task), pretende simular situações da vida quotidiana, reproduzindo dois tipos de condições: (1) situações onde a decisão se deve realizar sem que haja qualquer conhecimento sobre as suas implicações. Isto é, o sujeito desconhece completamente as consequências associadas a essa decisão; (2) situações onde a decisão se realiza com base num conhecimento probabilístico das consequências. Isto é, as consequências da decisão podem ser ponderadas em função de um conhecimento probabilístico associado à experiência das ocorrências. A primeira situação é definida como "incerteza" e a segunda como "risco".

A tarefa experimental constitui-se num jogo de cartas (atualmente digitalizado) onde o sujeito deve escolher sucessivamente uma carta de um conjunto de quatro baralhos possíveis (designados A, B, C, D). O objetivo é ganhar o máximo dinheiro possível ou evitar perder, sendo-lhe atribuído inicialmente $2000 €$ na versão portuguesa (Areias, Paixão, \& Couceiro, 2013). Associado à seleção de cada carta encontra-se uma recompensa monetária variável e, nalgumas cartas, também uma penalização monetária variável. Cada baralho tem uma sequência pré-definida de ganhos e perdas, embora isso não seja comunicado ao jogador. Os sujeitos desconhecem também o número de cartas por baralho e o número de escolhas que tem de fazer. Desconhecem ainda que há baralhos vantajosos e baralhos desvantajosos, isto é, que há baralhos que a longo prazo implicam necessariamente perdas e outros ganhos. No entanto, são informados que alguns baralhos são melhores que outros e que ganharão se se mantiverem "afastados" dos baralhos piores.

Os baralhos piores (desvantajosos) oferecem as recompensas mais altas por cada seleção, mas também punições mais elevadas. A frequência destas punições varia em função dos baralhos e das escolhas, mas a diferença entre ganhos e perdas é sempre negativa a longo prazo nos baralhos desvantajosos. Os baralhos melhores (vantajosos) oferecem por cada seleção recompensas mais baixas que os anteriores, mas também produzem perdas menos significativas, de total modo que a diferença entre ganhos e perdas é, a longo prazo, positiva nestes baralhos (Bechara, 2007).

Com esta distribuição de ganhos e perdas estabelece-se um conflito entre ganhos imediatos altos $e$ as consequências a longo prazo destas escolhas, substancialmente penalizadoras no caso dos baralhos desvantajosos (Paixão, 2016). A apreensão cognitiva disto, no entanto, só pode ser adquirida pela experiência de jogo, mas os sujeitos normais tendem a decidir vantajosamente antes de alcançarem esse conhecimento explícito, porque são guiados pelos marcadores somáticos que antecipam as emoções previamente desencadeadas pelas recompensas e punições associadas a cada baralho (idem). Esta marcação emocional das experiências facilita de forma eventualmente inconsciente a decisão porque, simplesmente, o "choque" da experiência de grandes perdas marca emocionalmente como "perigosos" os baralhos de recompensas imediatas muito altas. Os sujeitos com esta função emocional intacta tendem, então, a alterar as suas escolhas, mesmo antes de perceberem claramente os valores das pautas de recompensa (ganho) e punição (perda) associados a cada baralho.

No IGT as decisões iniciais são tomadas sob incerteza, mas a partir do momento em que são conhecidas as pautas de recompensa / punição a que nos referíamos antes, usualmente entre o ensaio 20 e $\circ 30$, passam a decisões sob risco (Paixão, 2016).

A tarefa permite o cálculo de múltiplos indicadores, para além do valor monetário alcançado no final do jogo, nomeadamente a evolução das escolhas dos baralhos ao longo do jogo, o que permite perceber a evolução da aprendizagem ao longo da tarefa. Estes resultados são apresentados tradicionalmente na forma de gráfico, calculando os valores médios por blocos de 20 ensaios ou jogadas. A análise, neste caso, centra-se particularmente no que acontece entre $\circ 2^{\circ}$ e $\circ 3^{\circ}$ bloco, isto é, a partir do momento em que é expetável o sujeito perceber a natureza de cada um dos baralho e a incerteza dar lugar ao risco. Outro aspeto interessante destas análises centra-se no estudo das frequências das recompensas e das punições, considerando que há baralhos com baixa frequência de punições e com ganhos líquidos em $90 \%$ das escolhas e baralhos com alta frequência de punições e ganhos líquidos em $50 \%$ dos ensaios. A análise destas frequências procura evidenciar padrões decisionais marcados pela frequência dos resultados positivos, mais do 
que pela quantidade efetiva de ganhos e perdas assim conseguida.

O enorme sucesso do IGT, como uma tarefa experimental, revê-se no número de resultados que podem ser obtidos googlando o descritor "lowa Gambling Task" (Areias et al., 2013; Paixão \& Areias, no prelo; Paixão, 2016). O número destes trabalhos, e as respetivas citações, evidencia que a tarefa tem sido utilizada nos mais variados estudos sobre psicopatologia e neuropsicologia, tal como identificamos no nosso estudo de 2016.

Muitos destes estudos, no entanto, têm evidenciado alguma variabilidade nos resultados, particularmente nos grupos de controlo, nomeadamente padrões de tomada de decisão sob incerteza e risco muito semelhantes aos evidenciados nos grupos clínicos. O fenómeno é mais nítido quando as populações clínicas, pelas suas condições socioeconómicas, exigem que os grupos de controlo incluam populações de extratos socioeconómicos baixos e muito baixos. Tal fenómeno é particularmente claro, por exemplo, nos grupos de controlo de populações de aditos de substâncias (Ernst et al., 2003; Tarter et al., 2003; Toplak, Jain, \& Tannock, 2005; Paixão, 2016).

Como referimos num outro trabalho:

\begin{abstract}
"Esta situação pode estar relacionada com a proximidade sociodemográfica destes grupos (particularmente os baixos rendimentos e variáveis associadas a essa característica) e, por essa razão, com o facto de ambos poderem ser, de igual modo, afetados por variáveis de vulnerabilidade e de risco. Bechara et al. (2001) sublinhou este ponto, ao referir que os sujeitos "normais" com padrões de decisão semelhantes aos pacientes com lesões pré-frontais ventromediais podem não ser simplesmente sujeitos que não aprendem a tarefa, mas que desenvolvem comportamentos decisionais desvantajosos, associados simplesmente a uma preferência pelo risco, excitação, e valorização da recompensa imediata. Muitos destes sujeitos preferem os baralhos com menor frequência de perdas ( $B$ e $D)$, em vez dos resultados a longo prazo, embora também seja possível que o conhecimento dos baralhos só ocorra tardiamente no jogo devido à baixa frequência de perdas nesses baralhos $B$ e $D$.
\end{abstract} (Paixão, 2016, p. 58).

Por essa razão, parte do nosso interesse atual está em perceber a natureza desta situação, por exemplo, em saber se as situações existenciais em que os sujeitos se encontram influenciam os seus padrões decisionais. Assumimos como hipótese que os padrões decisionais desvantajosos verificados em muitas populações de controlo se relacionam diretamente com o contexto socioeconómico em que vivem. O nosso trabalho de 2016 (Paixão, 2016) foca exatamente esse objetivo, evidenciando que os padrões decisionais em casais socioeconomicamente muito desfavorecidos são significativamente marcado por padrões decisionais desvantajosos. A nossa hipótese assenta na ideia de que estes padrões são correlativos de experiências de vida reféns da urgência da necessidade e, portanto, da desvalorização das decisões onde os ganhos estão diferidos no tempo (Paixão, 2016).

Em síntese, a ideia de que os processos decisionais podem estar relacionados com experiências de vida dominadas pelas grandes dificuldades socioeconómicas coloca algumas questões importantes, embora desconfortáveis, como as de saber se são esses padrões decisionais desvantajosos que determinam ou influenciam a frágil situação desses sujeitos ou se são essas fragilidades socioeconómicas que determinam ou influenciam esses padões decisionais; ou, ainda, se estas duas situações são circulares.

Independentemente das respostas possíveis a esta questão, a nossa hipótese é de que os dois fenómenos são circulares, mas com maior determinação da segunda resposta. Um dos pressupostos da teoria prospetiva de Kahneman (2002) assim o deixa antever, isto é, quando o resultado da ação tende a ser encarado como perda, os decisores tendem a maximizar o risco.

De outro modo, as fragilidades iniciadas nos ciclos de pobreza podem ter uma influência direta na maneira como as pessoas são levadas a decidir, particularmente porque a necessidade impõe respostas / recompensas no mais curto espaço de tempo e expetativas mais negativas em relação a essas recompensas. Respostas diferidas no tempo podem ser sentidas como inadequadas, dada a experiência de vida destes sujeitos, marcada pela urgência da necessidade atual. É quase como se (metaforicamente) a questão da "sobrevivência no dia-a-dia" tornasse irrelevante as eventuais ocorrências a longo prazo.

Atualmente, interessa-nos saber como se processa 
a tomada de decisão em situações da vida real, particularmente quando essas decisões são importantes para a sobrevivência do sujeito e da família em que se insere. Interessa-nos também perceber se há uma transmissão destes processos decisionais à descedência $e$, em caso de assim acontecer, como isso se processa.

Finalmente, esteé assunto que nos parece fundamental para o desenvolvimento das nossas sociedades e das populações em situação socioeconómica difícil.

\section{CONFLITOS DE INTERESSES}

Nenhum conflito financeiro, legal ou político envolvendo terceiros (governo, empresas e fundações privadas, etc.) foi declarado para nenhum aspecto do trabalho submetido (incluindo mas não limitandose a subvenções e financiamentos, conselho consultivo, desenho de estudo, preparação de manuscrito, análise estatística, etc).

\section{REFERÊNCIAS}

Areias, G., Paixão, R., \& Figueira, A.P.C. (2013). O lowa Gambling Task: Uma revisão crítica [The lowa Gambling Task: A critical revision]. Psicologia: Teoria e Pesquisa, 29(2), 201-210. doi: 10.1590/S010237722013000200009

Bechara, A. (2003). Risky business: emotion, decision-making, and addiction. Journal of Gambling Studies, 19(1), 23-51.

Bechara, A. (2007). lowa Gambling Task. Professional manual. Florida: Psychological Assessment Resources.

Bechara, A., Damasio, A.R., Damasio, H., \& Anderson, S.W. (1994). Insensitivity to future consequences following damage to human prefrontal cortex. Cognition, 50(13), 7-15.

Bechara, A., Damasio, H., \& Damasio, A.R. (2000). Emotion, decision making and the orbitofrontal cortex. Cerebral Cortex, 10(3), 295-307. doi: 10.1093/ cercor/10.3.295

Damasio, A.R. (1994). Descartes' error: emotion, reason and the human brain. New York: Grosset/Putnam.

Ernst, M., Grant, S.J., London, E.D., Contoreggi, C.S., Kimes, A.S., \& Spurgeon, L. (2003). Decision making in adolescents with behavior disorders and adults with substance abuse. The American Journal of Psychiatry, 160(1), 33-40. doi: 10.1176/appi.aip.160.1.33

Kahneman, D. (2012). Pensar, depressa e Devagar. Maia: Círculo dos Leitores.

Paixão, R. (2016). “A Tomada de Decisão sob incerteza e risco nos sistemas conjugais socioeconomicamente marginalizados". In Leila Tardivo (Org.), Anais da XIV Jornada Apoiar Saúde Mental e Interdisciplinaridade: Propostas e Pesquisas (pp.52-82). São Paulo: Vector.

Paixão, R., \& Areias, G. (no prelo). A Personalidade na Tomada de Decisão com o lowa Gambling Task: Uma Revisão Integrativa. Psicologia: teoria e pesquisa.

Tarter, R.E., Kirisci, L., Mezzich, A., Cornelius, J.R., Pajer, K., Vanyukov, M., et al. (2003). Neurobehavioral disinhibition in childhood predicts early age at onset of substance use disorder American Journal of Psychiatry, 160(6), 1078-1085. doi: 10.1176/appi. aip.160.6.1078

Toplak, M.E., Jain, U., \& Tannock, R. (2005). Executive and motivational processes in adolescents with attentiondeficit-hyperactivity disorder (ADHD). Behavioral and Brain Functions, 1(8), 1-12. doi: 10.1186/17449081-1-8 